\section{Changes in Physical Properties of Various Coir Dust and Perlite Mixes and Their Capacitance Sensor Volumetric Water Content Calibrations}

\author{
Yong Ha Rhie and Jongyun Kim ${ }^{1}$ \\ Division of Biotechnology, Korea University, Seoul 02841, Korea
}

Additional index words. dielectric sensor, soilless substrate, soil moisture sensor, total porosity, volumetric water content

\begin{abstract}
Recently developed capacitance soil moisture sensors are suitable for measuring volumetric water content (VWC, v/v) of soilless substrates in real time, useful for substrate moisture based-automated irrigation systems of horticultural crops. For capacitance sensors, a substrate-specific calibration is required for accurate VWC measurements, but sensor manufacturers typically provide only a general calibration for potting soil. However, the general calibration for potting soil is not indicative of the variety of soilless substrates. We investigated and compared the physical properties of various coir dust and perlite mix ratios $(1: 0,8: 2,6: 4,4: 6,2: 8,0: 1$, v/v), and conducted individual substrate-specific VWC calibrations in the range from $0.1 \mathrm{~m}^{3} \cdot \mathrm{m}^{-3}$ to near container capacity. Sensor outputs [in $\mathrm{mV}$ and analog-to-digital converter (ADC)] of various VWC levels of the specific substrates were collected with four EC-5 and GS3 sensors (Decagon Devices Inc., Pullman, WA) connected to a data logger with $2.5-\mathrm{V}$ and $12-\mathrm{V}$ excitation, respectively. Substrates with greater relative perlite contents had larger particles, and both the water-holding capacity and electrical conductivity (EC) were lower than the substrate mixes with more coir dust. All tested substrate mixes had linear relationship between EC-5 sensor output and VWC with high $R^{2}(>0.93)$ except in the case of $100 \%$ perlite, and their slopes were significantly different across the substrate mixes $(P=0.03)$. However, most of the substrate mixes had similar calibrations with estimated VWC differences within $0.06 \mathrm{~m}^{3} \cdot \mathrm{m}^{-3}$. The GS3 sensor had the best fit with a logarithmic relationship between sensor output (in ADC) and $\mathrm{VWC}$, and the slopes among the substrate mixes were not significantly different $(P=0.13)$. Furthermore, the soilless substrate calibration provided by the company differed from the substrate-specific calibration, resulting in considerable error (up to $0.18 \mathrm{~m}^{3} \cdot \mathrm{m}^{-3}$ difference), during the measurement of the actual VWCs. Therefore, sensor- and substrate-specific calibration is required for accurate VWC measurements with capacitance sensors.
\end{abstract}

Soilless culture is typical in vegetable and ornamental plant production as soilless substrates are virtually free of pests and disease, with superior water and oxygen availability compared with soils (Raviv and Lieth, 2008). Physical and chemical characteristics are easily manipulated with various soilless substrate materials (e.g., peatmoss, bark, perlite, Styrofoam, vermiculite, or rockwool) to obtain optimal conditions for plant growth (Bunt, 1988). In American or European countries, peatmoss is the most common base medium for soilless substrates; peatmoss

\footnotetext{
Received for publication 21 Sept. 2016. Accepted for publication 25 Oct. 2016.

This research was supported by Korea University Grant and Advanced Production Technology Development Program (313059-03) of Korea Institute of Planning and Evaluation for Technology in Food, Agriculture, Forestry, and Fisheries. ${ }^{1}$ Corresponding author. E-mail: jongkim@korea. ac.kr.
}

has great physical and chemical buffering properties for soilless substrates due to its high cation-exchange and water-holding capacities, good aeration, and resistance to decomposition (Fonteno, 1988). However, peatmoss is a finite natural resource, and due to this limitation (Barkham, 1993), many researchers have studied alternative materials for the same use. Among the potential alternatives, coir dust (i.e., coconut fiber or cocopeat) has been extensively used in the horticultural industry especially in Asian countries, as it is relatively inexpensive and more sustainable in that it can be derived from fresh fruit, while having similar physical and chemical properties to those of peatmoss (Konduru et al., 1999; Noguera et al., 2003). The physical properties of coir dust can differ on the basis of the country from which the material is sourced (e.g., Asia, tropical America, and Africa), and the total water-holding capacity increases as the particle size decreases (Abad et al., 2005). Coir dust has been tested as a soilless substrate for several ornamentals
(Evans and Stamps, 1996; Meerow, 1994) and vegetable transplant production (Arenas et al., 2002) with acceptable results. Therefore, many countries that have no peat production import coir dust with lower costs and use them as the main base for commercial soilless substrates (Handreck and Black, 2010; Josko, 1996).

Along with the sustainable horticultural substrate supply, another issue for this sustainable production is to implement efficient irrigation to reduce water and nutrient requirements. Recently developed sensor technology enables the irrigation of plants based on their actual water needs, which can improve efficiency in water and nutrient use in horticultural plant production (Lea-Cox et al., 2013). Among available sensor technologies, soil moisture sensors can provide growers with valuable information on substrate moisture conditions in real time, and precise irrigation to maintain specific substrate moisture conditions are available in conjunction with a data logger and solenoid valves (Kim et al., 2014). Currently, capacitance or frequency domain reflectometry sensors are regarded as the most suitable soil moisture sensors for automated irrigation systems in plant production, as they have several benefits such as easy maintenance, low costs, and more reliable readings than other types of soil moisture sensors (tensiometers, gypsum blocks, neutron probes) (Jones, 2004; van Iersel et al., 2013). Therefore, several studies have examined the use of capacitance sensors to automate irrigation of horticultural crops based on substrate moisture conditions, and their results indicate that soil moisture sensor-based automated irrigation systems worked effectively in plant production and in related fields (Bayer et al., 2013; Burnett and van Iersel, 2008; Cho et al., 2012; Nemali and van Iersel, 2008; Thompson et al., 2007). However, to properly interpret these capacitance soil moisture sensor measurements, proper calibration for specific soilless substrates is required (Nemali et al., 2007; van Iersel et al., 2013). Although most sensor manufacturers provide calibration coefficients for soilless substrates, grower-specific substrates make it difficult to devise one common calibration for the majority of soilless substrates; a global calibration equation for soilless substrate might not provide reliable interpretation of sensor readings for substrates such as coir dust and perlite mixtures. Improper calibration can lead to misinterpretation of valuable data, resulting in turn in erroneous information about plant responses under a certain substrate moisture level. In the current study, we investigated the physical properties and two chemical properties ( $\mathrm{pH}$ and $\mathrm{EC}$ ) of various substrates made of coir dust and perlite at various mixing ratios, and compared the capacitance sensor calibration equations among the different substrate mixing ratios and also with the calibration provided by the sensor manufacturer, to identify variations in substrate moisture sensor calibration. This could reveal the importance of substrate specific 
calibration, in particular for coir dust-based soilless substrate mixes.

\section{Materials and Methods}

Substrate preparation. Coir dust (Natural peat; EF Top, Yongin, Korea; originated from Sri Lanka) and perlite (New Pearl Shine No. 1; GFC Co., Hongseong, Chugnam, Korea) were mixed at ratios of $1: 0,8: 2,6: 4,4: 6,2: 8$, and $0: 1(\mathrm{v} / \mathrm{v})$ to investigate the physical properties of the substrate mix with different mixing ratios.

Physical and chemical properties of substrate mixes. The particle size distribution of each substrate mix was determined using $100 \mathrm{~g}$ oven-dried samples with three replicates. Each sample was placed on a series of U.S. standard sieves of 5.6, 2.8, 1.4, 0.710, $0.355,0.150$, and $0.106 \mathrm{~mm}$, and shaken for 5 min. Portions of the substrate samples remaining on each sieve were weighted and expressed as a percentage of the total sample weight. To determine the porosity properties of the substrate mixes, three replicates were filled in specific aluminum cylinders, following the procedures of Fonteno and Bilderback (1993). Three samples were used to determine the total porosity, container capacity, air space, and bulk density. These were defined as container capacity $=[($ wet weight dry weight)/volume of sample] $\times 100$; air space $=($ volume of water drained $/$ volume of sample) $\times 100$; total porosity $=$ container capacity + air space. Bulk density was calculated by dividing dry weight $\left(24 \mathrm{~h}\right.$ at $\left.105^{\circ} \mathrm{C}\right)$ by volume. Moisture retention curves of each substrate mix were determined using a sandbox apparatus (Eijkelkamp, Giesbeek, the Netherlands) at matric potentials of $0-10$ $\mathrm{kPa}$. Easily available water (EAW) and water-buffering capacity (WBC) were calculated from sandbox data using the difference in VWC between 1 and $5 \mathrm{kPa}$ suctions, and 5 and $10 \mathrm{kPa}$ water suctions, respectively (De Boodt and Verdonck, 1972). The $\mathrm{pH}$ and EC of each substrate mix were determined by the saturated media extract method using a $\mathrm{pH}$ meter (Accumet model 20; Fisher Scientific, Pittsburgh, PA) and EC meter (Orion 3 Star; Thermo Fisher Scientific Inc., Beverly, MA), respectively. Differences in the physical and chemical properties of the various coir dust and perlite mixes were tested through analysis of variance, followed by Tukey's honestly significant difference test for multiple comparison using SAS (SAS 9.4; SAS Institute, Cary, NC).

Capacitance sensor VWC calibration for various mix ratios. Four EC-5 sensors (Decagon Devices, Inc., Pullman, WA) and four GS3 sensors (Decagon Devices, Inc.) were used to conduct calibration of the capacitance sensor for VWC $(\mathrm{v} / \mathrm{v})$ measurement. Each sensor was connected to a CR1000 data logger (Campbell Scientific, Logan, UT), with excitation voltage at $2.5 \mathrm{~V}$ and $12 \mathrm{~V}$ for EC-5 and GS3, respectively. Since the GS3 sensor uses the SDI-12 communication protocol, GS3 sensors were connected to a control port of the data logger. To acquire VWC for each substrate mix, substrate mixes with 7-8 different moisture levels were prepared by adding distilled water and mixed thoroughly for contents of $0.1 \mathrm{~m}^{3} \cdot \mathrm{m}^{-3}$ to close to the water saturation level. To acquire more precise values for calibration, VWC calibration was conducted using $\%(\mathrm{v} / \mathrm{v})$ values according to the following formula:

$$
\begin{aligned}
& \operatorname{VWC}(\%) \\
& =\frac{\text { Wet substrate weight }(\mathrm{g})-\text { dry substrate weight }(\mathrm{g})}{\text { Container volume }(\mathrm{mL})} \\
& \quad \times 100
\end{aligned}
$$

When each substrate mix sample of a given VWC was made, the wet substrate weight was measured and sensor readings from the data logger with raw values (voltage output and ADC value from EC-5 and GS3, respectively) were recorded. After the substrates were fully dried at $105{ }^{\circ} \mathrm{C}$ until no weight change occurred, dry substrate weights were measured to calculate VWC. Regression analysis was conducted to estimate the calibration coefficients for each substrate mix, and their coefficients were compared with general linear models using SAS (SAS 9.4; SAS Institute). The calibration procedure was consistent with what the manufacturer uses for their factory calibrations to minimize technique effect.

\section{Results and Discussion}

Physical and chemical properties of the substrate mixes. Particle size distribution results (Fig. 1) displayed thorough mixing of the two substrate components in agreement with their predetermined mixing values. Coir dust used in the current study had

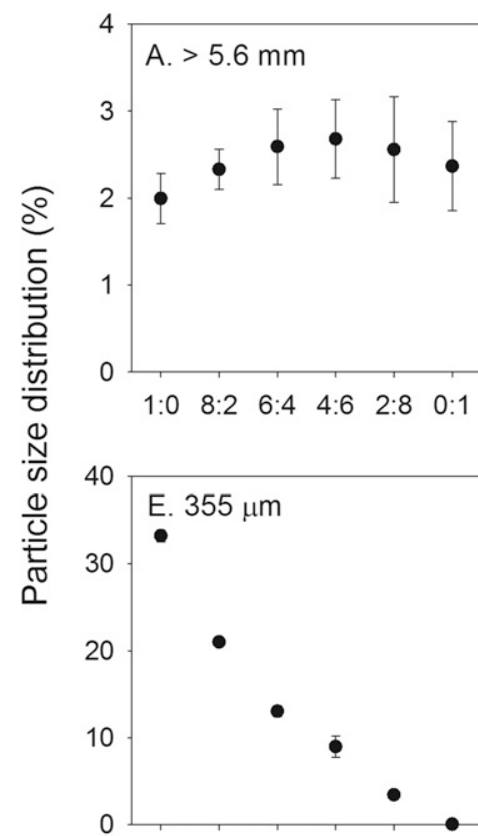

$\begin{array}{llllll}1: 0 & 8: 2 & 6: 4 & 4: 6 & 2: 8 & 0: 1\end{array}$
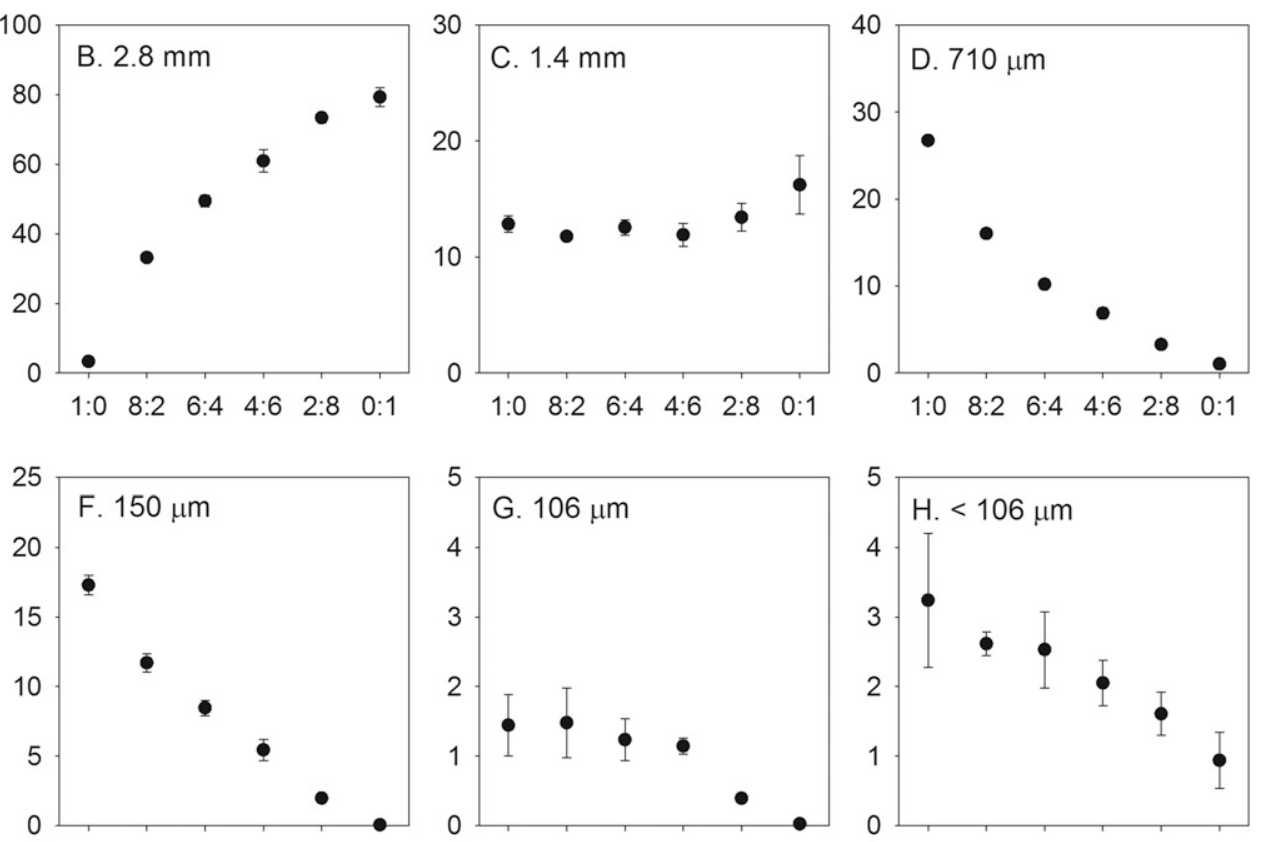

$\begin{array}{llllll}1: 0 & 8: 2 & 6: 4 & 4: 6 & 2: 8 & 0: 1\end{array}$
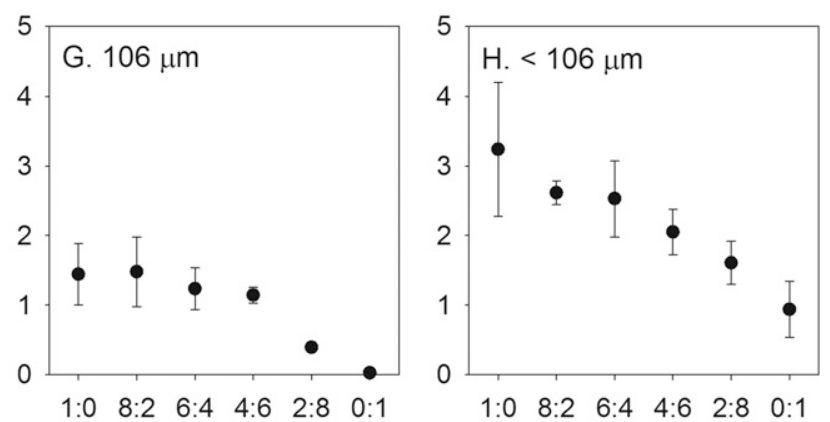

Substrate mixing ratio (coir dust:perlite, v/v)

Fig. 1. Particle distribution percentage at specific particle size of various coir dust and perlite mixes. The particle size distribution of each substrate mix was determined using $100 \mathrm{~g}$ oven-dried samples. Each sample was placed on a series of U.S. standard sieves with different screening sizes, and shaken for $5 \mathrm{~min}$. Portions of the substrate samples remaining on each sieve were weighted and expressed as a percentage of the total sample weight. Error bars indicate $\operatorname{SES}(\mathrm{n}=3)$ 
Table 1. Physical and chemical properties of various coir dust and perlite mixes (1:0, 8:2, 6:4, 4:6, 2:8, and 0:1).

\begin{tabular}{|c|c|c|c|c|c|c|}
\hline $\begin{array}{l}\text { Substrate mix } \\
\text { (coir dust:perlite, v/v) }\end{array}$ & $\begin{array}{c}\text { Container } \\
\text { capacity }(\%)\end{array}$ & $\begin{array}{c}\text { Air } \\
\text { space }(\%)\end{array}$ & $\begin{array}{c}\text { Total } \\
\text { porosity }(\%)\end{array}$ & $\begin{array}{c}\text { Bulk } \\
\text { density }\left(\mathrm{g} \cdot \mathrm{cm}^{-3}\right)\end{array}$ & $\mathrm{pH}$ & $\begin{array}{c}\text { Electrical } \\
\text { conductivity }\left(\mathrm{dS} \cdot \mathrm{m}^{-1}\right)\end{array}$ \\
\hline $8: 2$ & $60.6 \mathrm{ab}$ & $27.0 \mathrm{~b}$ & $87.5 \mathrm{ab}$ & $0.08 \mathrm{e}$ & $5.12 \mathrm{de}$ & $0.76 \mathrm{a}$ \\
\hline $6: 4$ & $58.0 \mathrm{bc}$ & $26.7 \mathrm{~b}$ & $84.7 \mathrm{abc}$ & $0.10 \mathrm{~d}$ & $5.24 \mathrm{~d}$ & $0.52 \mathrm{~b}$ \\
\hline $2: 8$ & $38.4 \mathrm{~d}$ & $39.9 \mathrm{a}$ & $78.3 \mathrm{~cd}$ & $0.13 \mathrm{~b}$ & $6.62 \mathrm{~b}$ & $0.18 \mathrm{c}$ \\
\hline$\underline{0: 1}$ & $24.5 \mathrm{e}$ & $45.0 \mathrm{a}$ & $69.5 \mathrm{~d}$ & $0.14 \mathrm{a}$ & $8.74 \mathrm{a}$ & $0.06 \mathrm{c}$ \\
\hline
\end{tabular}

Means followed by the same letters are not significantly different followed by Tukey's honest significant difference test at $\alpha=0.05$.

particles of size in the range $0.15-2.8 \mathrm{~mm}$, and perlite had relatively larger particles (primarily $>2.8 \mathrm{~mm}$ ). As the amount of perlite increased, the ratio of larger particles increased, thus increasing the macropore contents in the substrate mix. Percentage of large particles $(2.8-5.6 \mathrm{~mm})$ increased as more perlite was mixed in the substrate mix, and the percentage of smaller particles $(<710 \mu \mathrm{m})$ increased as more coir dust was added to the substrate mix (Fig. 1). More than $60 \%$ of the particles in the $100 \%$ coir dust and 8:2 (coir dust:perlite, v/v) samples were within the optimum particle size range $(0.25-2.0 \mathrm{~mm})$, but substrate mixes containing $>40 \%$ perlite had an excess of larger $(>2.8 \mathrm{~mm})$ particles (Abad et al., 2001), which caused a decrease in the water-holding capacity.

Container capacity was highest in the $100 \%$ coir dust, and decreased as the perlite contents increased (Table 1). Air space was highest in $100 \%$ perlite $(45 \%)$, and decreased significantly to $26.3 \%$ at a coir dust ratio of $40 \%$. No significant differences in air space were found when the coir dust portion was higher than $40 \%$. Total porosity decreased as the perlite contents increased, indicating that coir dust could provide more micropores to enhance the total porosity of the substrate mix (Evans and Stamps, 1996). Bulk density was lowest in $100 \%$ coir dust, and increased significantly as the perlite contents increased $(P<0.001)$. The $\mathrm{pH}$ of $100 \%$ coir dust was 4.99 , whereas that of $100 \%$ perlite was 8.74 . The $\mathrm{pH}$ of substrate mixes increased as the perlite contents increased $(P<0.001)$, but mixtures of coir dust and perlite could maintain weak acidic condition $(\mathrm{pH}<7.0)$ even at 2:8 (coir dust:perlite) substrate mix. The EC of $100 \%$ coir dust was $0.84 \mathrm{dS} \cdot \mathrm{m}^{-1}$, and decreased with increasing amounts of perlite (Table 1). Although VWC calibration might change due to EC ranges, EC values for the substrate mixes were within the EC ranges for factory calibration (Decagon Devices, 2016a, 2016b).

Moisture release curves are frequently used to predict water availability to plants and for irrigation management (Raviv and Lieth, 2008). We determined moisture release curves using a sandbox apparatus, and EAW and WBC were calculated from these sandbox results (Fig. 2). As the amount of perlite increased, the volumetric content of EAW decreased linearly, indicating less water releasing potential to the plants, and thus, necessitating more frequent irrigation. Although $100 \%$ coir dust had $29.6 \%$ EAW, $100 \%$ perlite only had $4.1 \%$. When WBC is

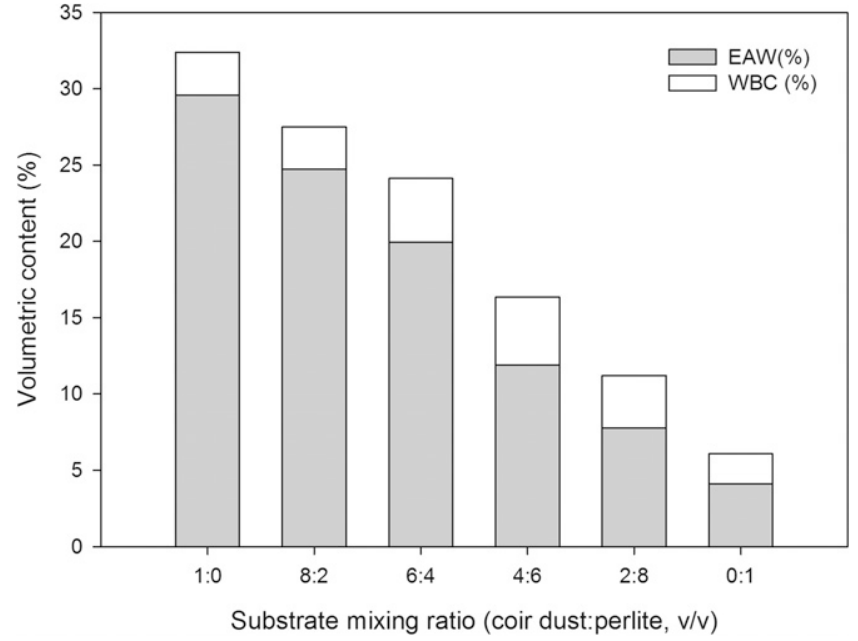

Fig. 2. Easily available water (EAW) and water-buffering capacity (WBC) of different substrate mixes between coir dust and perlite. EAW and WBC was calculated from sandbox data using the difference of volumetric water content between 1 and $5 \mathrm{kPa}$ suctions, and 5 and $10 \mathrm{kPa}$ suctions, respectively.

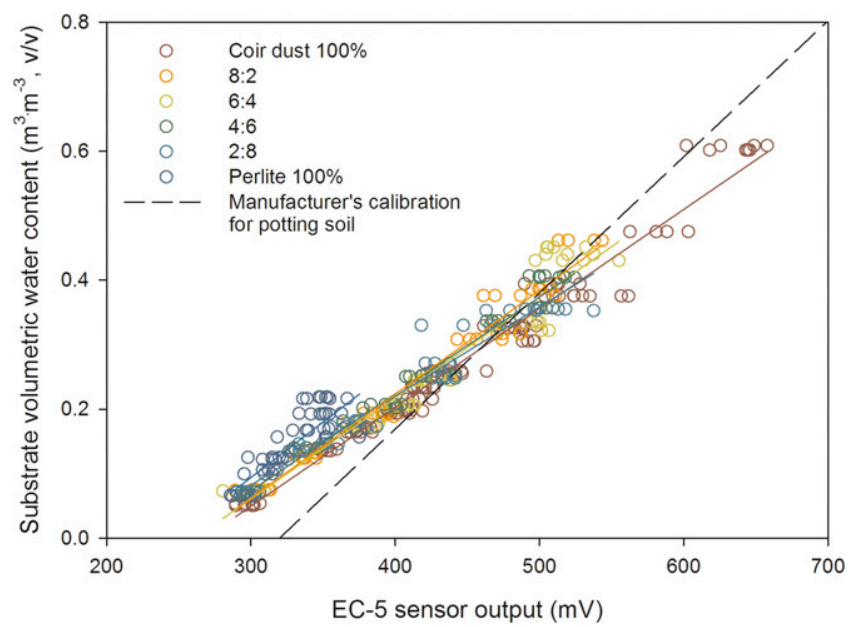

Fig. 3. EC-5 soil moisture sensor (Decagon Devices Inc., Pullman, WA) volumetric water content (v/v, \%) calibration for various coir dust and perlite mixes. Sensors were connected to a CR1000 data logger (Campbell Scientific, Logan, UT) with 2.5-V excitation voltage.

also considered, the available water content (VWC between 1 and $10 \mathrm{kPa}$ suction) of the substrate mixes decreased as the amount of perlite increased. These results are similar to those of Cho et al. (2006), who demonstrated that the available water content was six times higher in coir than in perlite, and available water contents in coir-based mixtures decreased as the percentage of perlite increased.

Capacitance sensor VWC calibration for various mix ratios. For our sensor-specific calibrations with various coir dust and perlite mixes, both EC-5 and GS3 soil moisture sensors displayed good calibration fits with $r^{2}>0.93$ for all the substrate mixes other than $100 \%$ perlite (Tables 2 and 3). Since $100 \%$ perlite had a very large particle size with a low VWC range because of its container capacity (maximum of $0.24 \mathrm{~m}^{3} \cdot \mathrm{m}^{-3}$ ), the VWC might have very low uniformity, corresponding to low $r^{2}$ of 0.72 and 0.89 for EC-5 and GS3, respectively. Raw values from 
EC-5 sensors showed a linear relationship with VWC, but their slopes were significantly different across the different substrate mixes $(P=0.025)$ (Fig. 3). Among the substrate mixes from 8:2 to 2:8 (coir dust:perlite, $\mathrm{v} / \mathrm{v}$ ), slopes of the calibration curves decreased slightly and the $y$ intercept increased as the perlite portion increased. Although there were significant differences in calibration coefficients among the substrate mixes, their differences in estimated VWCs were less than $0.06 \mathrm{~m}^{3} \cdot \mathrm{m}^{-3}$; if the container capacity of each substrate mix was considered, the difference in VWC estimation among the different calibrations was $<0.04 \mathrm{~m}^{3} \cdot \mathrm{m}^{-3}$. Specific calibration for each substrate should be

Table 2. EC-5 sensor calibration coefficients for different substrate mixing ratios between coir dust and perlite. Volumetric water content $(\mathrm{v} / \mathrm{v}$, $\%)=\alpha \times$ sensor output $(\mathrm{mV})+\beta$.

\begin{tabular}{lccc}
\hline $\begin{array}{l}\text { Substrate mix } \\
\text { (coir dust:perlite) }\end{array}$ & $\alpha$ & $\beta$ & $r^{2}$ \\
\hline $1: 0$ & 0.1534 & -41.0706 & 0.9691 \\
$8: 2$ & 0.1611 & -42.1462 & 0.9691 \\
$6: 4$ & 0.1564 & -40.8578 & 0.9386 \\
$4: 6$ & 0.1502 & -37.7234 & 0.9713 \\
$2: 8$ & 0.1381 & -33.2221 & 0.9476 \\
$0: 1$ & 0.1719 & -42.1864 & 0.7167 \\
\hline
\end{tabular}

$P$ values for all the regression analyses were less than 0.001 .

Table 3. GS3 sensor calibration coefficients for different substrate mixing ratios between coir dust and perlite. Volumetric water content (v/v, $\%)=\alpha \times \ln ($ sensor output in analog-to-digital converter) $+\beta$.

\begin{tabular}{lccc}
\hline $\begin{array}{l}\text { Substrate mix } \\
\text { (coir dust:perlite) }\end{array}$ & $\alpha$ & $\beta$ & $r^{2}$ \\
\hline $1: 0$ & 19.1851 & -2.1356 & 0.9691 \\
$8: 2$ & 20.0257 & -2.9219 & 0.9775 \\
$6: 4$ & 20.6121 & -4.4712 & 0.9507 \\
$4: 6$ & 20.7300 & -6.0365 & 0.9611 \\
$2: 8$ & 20.4761 & -6.3105 & 0.9305 \\
$0: 1$ & 19.9040 & -5.9254 & 0.8881 \\
\hline
\end{tabular}

$P$ values for all the regression analyses were less than 0.001 . required for precise measurement and control of VWC, but global calibration coefficients for certain type of substrate mixes may be acceptable for practical usage in commercial production with an automated irrigation system with soil moisture sensors. In comparison with the calibration coefficients for soilless substrates (potting soil) provided by the manufacturer (Decagon Devices, 2016a), estimation of VWC from the manufacturer calibration was similar to our calibrations around $0.3 \mathrm{~m}^{3} \cdot \mathrm{m}^{-3}$, but estimated much higher VWCs at higher ranges $\left(>0.5 \mathrm{~m}^{3} \cdot \mathrm{m}^{-3}\right)$, and much lower VWCs at lower ranges $\left(<0.2 \mathrm{~m}^{3} \cdot \mathrm{m}^{-3}\right)$ (Fig. 3). Therefore, to make proper use of capacitance sensors with specific soilless substrates, a proper calibration for the specific substrate may be necessary.

By comparison, different from the fact that EC-5 sensors express a linear relationship between sensor output and VWC, GS3 sensors had a better fit with a logarithmic relationship between sensor output (ADC) and VWC (Table 3; Fig. 4), and their calibration coefficients for slope were not significantly different for different substrate mixes $(P=0.1259)$. There were only slight differences in the $y$ intercept, which decreased with increasing amounts of perlite in the substrate mixes, but the VWC estimation difference was less than $0.04 \mathrm{~m}^{3} \cdot \mathrm{m}^{-3}$. The calibration equation provided by the manufacturer for soilless substrates (potting soil) was a square root relationship between sensor output (ADC) and VWC (Decagon Devices, 2016b), estimating VWCs much lower than the actual VWCs (Fig. 4). The difference in estimated VWCs between the calibration from the current study and manufacturer's calibration was as much as $0.18 \mathrm{~m}^{3} \cdot \mathrm{m}^{-3}$, when the actual VWC was $\approx 0.4 \mathrm{~m}^{3} \cdot \mathrm{m}^{-3}$. If no proper calibration for a specific substrate is used, and only the provided calibration coefficients are used, these erroneous VWC estimations would lead to wrong interpretation of research data and overwatering of the crops when used in commercial production with automated irrigation systems, thus providing

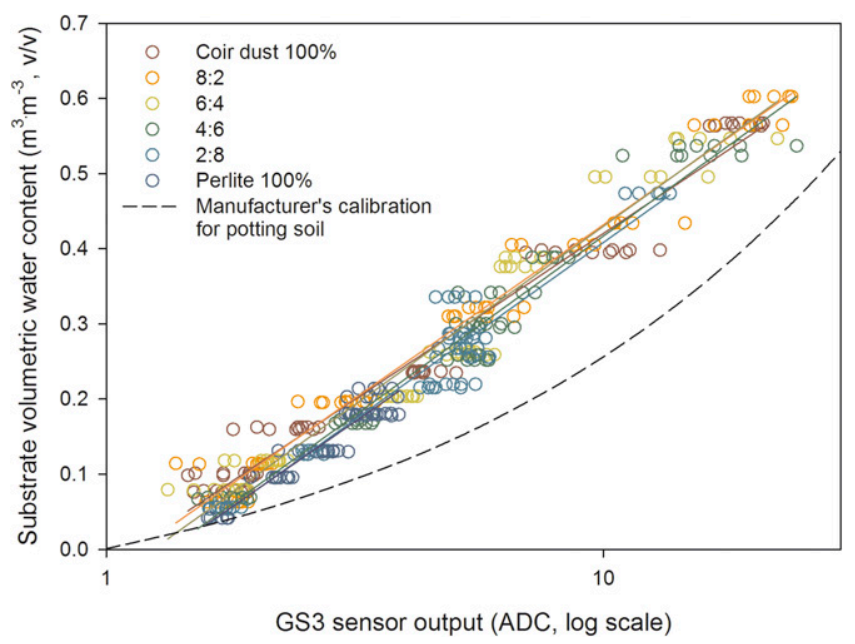

Fig. 4. GS3 soil moisture sensor (Decagon Devices Inc., Pullman, WA) volumetric water content (v/v, \%) calibration for various coir dust and perlite mixes. Sensors were connected to a CR1000 data logger (Campbell Scientific, Logan, UT) through SDI-12 protocol with 12-V excitation voltage. overly wet conditions for the substrates. Although the manufacturer's calibration coefficients for substrates in specific sensors were from multiple tests with several substrates, they also suggest performing substrate-specific calibrations to improve VWC estimation.

Although the physical (porosity, bulk density, and the available water contents) and chemical ( $\mathrm{pH}$ and EC) properties of the substrate mixes were significantly different across the different mixing ratios, our capacitance sensor calibrations did not differ significantly. However, the calibration coefficients from the sensor manufacturer showed different VWC estimations with current samples of coir dust and perlite, probably due to different base media for the substrates (i.e., peatmoss) that the manufacturer tested for soilless substrates calibration. Further research may be required to compare the capacitance sensor calibration equations across different base media, but to properly measure VWC with a capacitance sensor, substrate-specific calibration is necessary for higher accuracy.

\section{Conclusions}

Although VWC calibrations of substrate mixes with different coir dust and perlite ratios differed somewhat based on ratio, their differences in VWC estimation were not huge. Although a global calibration value may be suitable for commercial production with their own set point ranges, a specific calibration for each substrate may be necessary to obtain proper VWC estimation from capacitance sensors. For improving our knowledge of plant responses to different soil moisture levels, capacitance sensors that provide good information about substrate moisture conditions are required, and proper calibration is necessary to obtain reliable, accurate data.

\section{Literature Cited}

Abad, M., F. Fornes, C. Carrión, V. Noguera, P. Noguera, Á. Maquieira, and R. Puchades. 2005. Physical properties of various coconut coir dusts compared to peat. HortScience 40:2138-2144.

Abad, M., P. Noguera, and S. Burés. 2001. National inventory of organic wastes for use as growing media for ornamental potted plant production: Case study in Spain. Bioresour. Technol. 77:197-200.

Arenas, M., C.S. Vavrina, J.A. Cornell, E.A Hanlon, and G.J. Hochmuth. 2002. Coir as an alternative to peat in media for tomato transplant production. HortScience 37:309-312.

Barkham, J.P. 1993. For peat's sake: Conservation or exploitation? Biodivers. Conserv. 2:556-566.

Bayer, A., I. Mahbub, M. Chappell, J. Ruter, and M.W. van Iersel. 2013. Water use and growth of Hibiscus acetosella 'Panama Red' grown with a soil moisture sensor-controlled irrigation system. HortScience 48:980-987.

Bunt, A.C. 1988. Media and mixes for container grown plants: A manual on the preparation and use of growing media for growing pot plants. Unwyn Hyman, London, UK

Burnett, S.E. and M.W. van Iersel. 2008. Morphology and irrigation efficiency of Gaura lindheimeri grown with capacitance sensor-controlled irrigation. HortScience 43:1555-1560. 
Cho, Y.H., E.S. Kim, H.K. Kang, and Y.M. Cheong. 2012. A study on characteristics of seed germination of native plants for revegetation on the slope of river bank. J. Korea Soc. Environ. Restoration Technol. 15:103-115.

Cho, M-S., Y-Y. Park, H-J. Jun, and J-B. Chung. 2006. Growth of gerbera in mixtures of coir dust and perlite. Hort. Environ. Biotechnol. 47:211-216.

De Boodt, M. and O. Verdonck. 1972. The physical properties of the substrates in horticulture. Acta Hort. 26:37-44.

Decagon Devices. 2016a. EC-5 soil moisture sensor. Decagon Devices, Inc. 24 Oct. 2016. <http:// manuals.decagon.com/Manuals/13876_EC-5_ Web.pdf $>$.

Decagon Devices. 2016b. GS3 water content, EC, and temperature sensors. Decagon Devices, Inc. 24 Oct. 2016. <http://manuals.decagon. com/Manuals/13822_GS3_Web.pdf $>$.

Evans, M.R. and R.H. Stamps. 1996. Growth of bedding plants in sphagnum peat and coir dustbased substrates. J. Environ. Hort. 14:187-190.

Fonteno, W.C. 1988. An approach to modeling air and water status of horticultural substrates. Acta Hort. 238:67-74.

Fonteno, W.C. and T.E. Bilderback. 1993. Impact of hydrogel on physical properties of coarse-structured horticultural substrates. J. Amer. Soc. Hort. Sci. 118:217-222.

Handreck, K. and N. Black. 2010. Growing media for ornamental plants and turf. UNSW Press, Sydney, Australia.

Jones, H.G. 2004. Irrigation scheduling: Advantages and pitfalls of plant-based methods. J. Expt. Bot. 55:2427-2436.

Josko, D.L. 1996. On-coir. Greenhouse Business $2: 30$.

Kim, J., J.D. Lea-Cox, M. Chappell, and M.W. van Iersel. 2014. Wireless sensors networks for optimization of irrigation, production, and profit in ornamental production. Acta Hort. 1037:643-650.

Konduru, S., M.R. Evans, and R.H. Stamps. 1999. Coconut husk and processing effects on chemical and physical properties of coconut coir dust. HortScience 34:88-90.

Lea-Cox, J.D., W.L. Bauerle, M.W. van Iersel, G.F. Kantor, T.L. Bauerle, E. Lichtenberg, D.M. King, and L. Crawford. 2013. Advancing wireless sensor networks for irrigation management of ornamental crops: An overview. HortTechnology 23:717-724.

Meerow, A.W. 1994. Growth of two subtropical ornamentals using coir (coconut mesocarp pith) as a peat substitute. HortScience 29:1484 1486.

Nemali, K.S., F. Montesano, S.K. Dove, and M.W. van Iersel. 2007. Calibration and performance of moisture sensors in soilless substrates: $\mathrm{ECH}_{2} \mathrm{O}$ and Theta probes. Scientia Hort. 112:227-234.

Nemali, K.S. and M.W. van Iersel. 2008. Physiological responses to different substrate water contents: Screening for high water-use efficiency in bedding plants. J. Amer. Soc. Hort. Sci. 133:333-340.

Noguera, P., M. Abad, R. Puchades, A. Maquieira, and V. Noguera. 2003. Influence of particle size on physical and chemical properties of coconut coir dust as container medium. Commun. Soil Sci. Plant Anal. 34:593-605.

Raviv, M. and J.H. Lieth. 2008. Soilless culture: Theory and practice. Elsevier, San Diego, CA.

Thompson, R.B., M. Gallardo, L.C. Valdez, and M. D. Fernández. 2007. Using plant water status to define threshold values for irrigation management of vegetable crops using soil moisture sensors. Agr. Water Mgt. 88:147-158.

van Iersel, M.W., M. Chappell, and J.D. Lea-Cox. 2013. Sensors for improved efficiency of irrigation in greenhouse and nursery production. HortTechnology 23:735-746. 